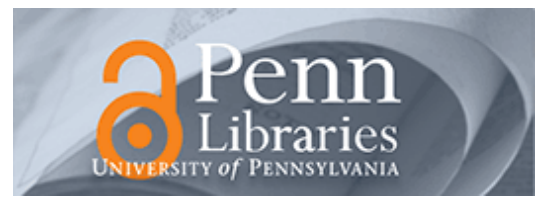

University of Pennsylvania

ScholarlyCommons

Finance Papers

Wharton Faculty Research

2010

\title{
Limited Participation and Consumption-Saving Puzzles: A Simple Explanation and the Role of Insurance
}

Todd A. Gormley

University of Pennsylvania

Hong Liu

Guofu Zhou

Follow this and additional works at: https://repository.upenn.edu/fnce_papers

Part of the Finance Commons, and the Finance and Financial Management Commons

\section{Recommended Citation}

Gormley, T. A., Liu, H., \& Zhou, G. (2010). Limited Participation and Consumption-Saving Puzzles: A Simple Explanation and the Role of Insurance. Journal of Financial Economics, 96 (2), 331-344. http://dx.doi.org/ 10.1016/j.jineco.2010.01.001

This paper is posted at ScholarlyCommons. https://repository.upenn.edu/fnce_papers/371

For more information, please contact repository@pobox.upenn.edu. 


\title{
Limited Participation and Consumption-Saving Puzzles: A Simple Explanation and the Role of Insurance
}

\author{
Abstract \\ In this paper, we show that the existence of a large, negative wealth shock and insufficient insurance \\ against such a shock could explain both the limited stock market participation puzzle and the low- \\ consumption-high-savings puzzle. We then conduct an empirical analysis on the relation between \\ household portfolio choices and access to private insurance and various types of government safety \\ nets. The empirical results demonstrate that a lack of insurance against large, negative wealth shocks is \\ positively correlated with lower participation rates and higher saving rates. Overall, the evidence suggests \\ an important role of insurance in household investment and savings decisions.

\section{Disciplines} \\ Finance | Finance and Financial Management
}




\title{
Limited Participation and Consumption-Saving Puzzles: A Simple Explanation and the Role of Insurance
}

\author{
Todd Gormley, Hong Liu and Guofu Zhou*
}

Current version: June 2009

\footnotetext{
${ }^{*}$ All authors are from Washington University in St Louis. We thank Thorsten Beck, Jian Cai, John Campbell, Phil Dybvig, Michael Faulkender, Campbell Harvey, Juhani Linnainmaa, Mark Loewenstein, Anthony Lynch (AFA discussant), David McLean (FIRS discussant), G.William Schwert (the managing editor), Costis Skiadas, Rong Wang, Kangzhen Xie, conference participants of the 2009 American Finance Association meetings and 2008 Financial Intermediation Research Society meetings, seminar participants at Washington University in St. Louis, and especially an anonymous referee for insightful and detailed comments that substantially improved the paper.
}

Corresponding Author: Professor Guofu Zhou, Olin Business School, Washington University, St. Louis, MO 63130. Phone: (314) 935-6384 and e-mail: zhou@wustl.edu 


\title{
Limited Participation and Consumption-Saving Puzzles: A Simple Explanation and the Role of Insurance
}

\begin{abstract}
In this paper, we use a simple model to illustrate that the existence of a large, negative wealth shock and insufficient insurance against such a shock can potentially explain both the limited stock market participation puzzle and the low-consumption-high-savings puzzle that are widely documented in the literature. We then conduct an extensive empirical analysis on the relation between household portfolio choices and access to private insurance and various types of government safety nets, including social security and unemployment insurance. The empirical results demonstrate that a lack of insurance against large, negative wealth shocks is strongly correlated with lower participation rates and higher saving rates. Overall, the evidence suggests an important role of insurance in household investment and savings decisions.

Journal of Economic Literature Classification Numbers: D11, D91, G11, C61.

Keywords: Limited participation, Insurance, Saving, Consumption
\end{abstract}


As Campbell states in his 2006 presidential address: "Textbook financial theory implies that all households, no matter how risk averse, should hold some equities if the equity premium is positive." But, it is well documented that less than 50 percent of households in the U.S., and far less in many other countries, participate in the stock market, ${ }^{1}$ and that this limited participation has a significant impact on the equilibrium risk premium, diversification discount, liquidity, and market crashes. ${ }^{2}$ It is also well documented that relative to their income, households in developing countries consume less and save more than those in developed countries (Cao and Modigliani, 2004). This gap is puzzling especially given the explicit effort by governments in many developing countries to discourage saving and promote consumption as a way to reduce dependence on foreign demand for economic growth.

While there exist several possible explanations for the limited participation puzzle and the low-consumption-high-savings (LCHS) puzzle, there is little overlap in these explanations. The existing explanations for limited participation rates generally rely on either transactions costs (Vissing-Jorgensen, 2002), the existence of both learning and short-sale constraints for investors whose income has a positive correlation with the stock market (Linnainmaa, 2005), or nonstandard preferences, where nonparticipation can be optimal for investors with ambiguity or disappointment aversion (Dow and Werlang, 1992; Ang, Bekaert, and Liu, 2005; Epstein and Schneider, 2007; and Cao, Wang, and Zhang, 2005). Existing explanations for the LCHS puzzle, however, generally take different routes and tend to rely on demographic structure and inflation (Cao and Modigliani, 2004), credit constraints and a desire to purchase durable goods (Chamon and Prasad, 2006), or a combination of habit-formation and rapid economic growth (Carroll and Weil, 2000; Carroll, Overland, and Weil, 1994, 1997).

In this paper, we demonstrate that a single driving force, insufficient insurance against

\footnotetext{
${ }^{1}$ See, for example, Mankiw and Zeldes, 1991; Haliassos and Bertaut, 1995; Heaton and Lucas, 2000; and Guiso, Haliassos, and Jappelli, 2003.

${ }^{2}$ See, for example, Basak and Cuoco, 1998; and Huang and Wang, 2007.
} 
large negative shocks, might help explain both the limited participation and the LHCS puzzles. Using the insights of Elmendorf and Kimball (2000) that labor income risk (and the lack of insurance against such risk) can affect both consumption and risky asset holding, we conduct an extensive empirical analysis, at both the country- and household-level, to analyze the relationship between stock market participation, saving, and insurance. We find substantial evidence that a lack of insurance against large, negative wealth shocks is strongly correlated with both lower participation rates and higher saving rates. The evidence strongly supports the theoretical result of Elmendorf and Kimball (2000) that insurance may play a role in both household investment and savings decisions.

To help illustrate the potential role of insurance in resolving both puzzles, we use a simple model to highlight how the exposure to a large, negative wealth shock, such as a loss of a job or a bad health shock, affects household portfolio choices. We show that if there exists a negative wealth shock where an investor needs almost all current wealth to finance subsistence level consumption, then a rational investor saves almost all of his current wealth and does not participate in the stock market at all - even if the probability of such a shock is arbitrarily small and the expected stock return is high. ${ }^{3}$ This is because the investor needs almost all of his current wealth to absorb the negative wealth shock and to maintain the subsistence level of consumption if such a shock occurs. This explanation is economically intuitive and does not require nonstandard preferences, fixed costs or a positive income beta with short-sale constraints; nor does it require income growth or demographic shifts.

The model implies an important role insurance markets can play in participation and saving decisions, which has not received much attention in the asset pricing literature. If there is an insurance market for hedging the wealth shock, an investor will optimally participate in the stock market, consume more, and save less. If the probability of the negative wealth

\footnotetext{
${ }^{3}$ This is qualitatively consistent with Polkovnichenko (2007) who finds that with uninsurable stochastic income and habit-formation preferences, investment becomes more conservative.
} 
shock is small and thus buying insurance is inexpensive, then the investor may even consume almost all of his current wealth and save virtually nothing if his expected future wealth is high. The presence of government safety nets, which insure against such adverse shocks, will have similar implications. Overall, the model indicates that availability of insurance can dramatically change an investor's consumption, saving, and investment decisions. ${ }^{4}$

Country-level empirical analysis provides strong support for a connection between insurance, participation rates, and saving. We find that stock market participation rates across countries are positively correlated with the presence of a large, private insurance market. This correlation holds strongly even after we control for other country-level characteristics shown to be important in the existing literature, including measures of investor protection, trust, legal origin, and economic development. In addition, access to insurance markets is negatively correlated with saving rates of households, particularly in developing countries where households face arguably greater exposure to large, negative wealth shocks. The presence of public insurance, as captured by government safety nets such as a large social security program, is also positively related to participation levels and negatively related to saving rates. Finally, we find that consistent with the model prediction, participation and saving rates are negatively correlated at the country-level.

Our empirical evidence is not limited to country-level correlations between the availability of insurance, participation rates, and saving rates. We also find evidence that differences in the generosity of unemployment insurance programs across U.S. states is positively related to stock market participation levels in those states. This finding holds even if we account for individual household characteristics, such as age, income, wealth, race, marriage, risk tolerance, and after controlling for state-level differences in the average level of education and economic

\footnotetext{
${ }^{4}$ This theoretical result also conforms with recent policy advice given by U.S. Treasury Secretary Geithner. News reports indicate that Secretary Geithner has urged China to stimulate domestic consumption by improving its social safety net through better pensions and health care. See "Geithner's China Pitch", Wall Street Journal Asia, June 4, 2009.
} 
development. Consistent with our theory, the positive relation between unemployment insurance generosity and participation levels is also particularly strong in those U.S. states where a larger fraction of workers are exposed to employment risk, as captured by greater employment in declining industries. This evidence suggests that social safety nets and access to insurance affect individuals' portfolio decisions even in developed countries.

Finally, we find evidence that the likelihood of a U.S. household holding risky stocks is positively correlated with the extent to which the household is insured against an adverse health shock. U.S. households that are insured against large, adverse health shocks - as captured by having an employer-sponsored health policy, life insurance policy, or long-term care policy - are more likely to hold risky stocks after controlling for various household characteristics including age, wealth, education, and income. ${ }^{5}$

Overall, our paper finds strong empirical evidence that access to both public and private insurance is related to households' portfolio decisions. The evidence suggests that access to insurance may play an important role in explaining both the limited participation puzzle and the LCHS puzzle and in understanding household investment behavior and asset pricing in general.

Our empirical evidence also provides substantial support to the large literature on precautionary saving against background risk (e.g., Kimball, 1992; Eeckhoudt and Kimball, 1992; Kimball, 1993; Elmendorf and Kimball, 2000; Carroll, 2001; Carroll and Kimball, 2008). Kimball (1993) demonstrates that with standard risk aversion, in the presence of the zero-mean background risk, an investor will invest less in the risky asset and save more. Elmendorf and Kimball (2000) discuss the effect of undesirable risk on both consumption and risky asset holding. Although they focus on the effect of income taxes in providing implicit insurance,

\footnotetext{
${ }^{5}$ While not tested in this paper, there are also a number of empirical studies that find access to health insurance is negatively related to saving rates. (E.g., Gruber and Yelowitz, 1999; Chou, Liu, and Hammitt, 2003; Goldman and Maestas, 2005; and Qiu, 2006). These findings are also consistent with our hypothesis.
} 
the math clearly applies to other types of insurance, and they show that large shocks can have powerful effects. ${ }^{6}$ Using numerical simulations, Carroll (2001) also shows that large shocks can have a significant impact on saving and an even greater impact on risky asset investment, even when the probability of such shocks is small.

The rest of the paper is organized as follows. In Section 1, we use a simple model to illustrate the impact insurance can have on household participation and saving rates. In Section 2, we document the empirical relation between household portfolio choices and access to insurance, and in Section 3, we offer some concluding remarks.

\section{The Model}

\subsection{Saving and Stock Investment without Insurance}

Using key insights from Elmendorf and Kimball (2000), we consider a simple, two-period model where an investor with an initial wealth of $W_{0}$ derives utility from consumption today $c_{0}$ and consumption next period $c_{1}$. His wealth endowment next period is $\tilde{W}_{1}$, where, with a small probability $\epsilon>0, \tilde{W}_{1}=-D<0$, which represents a negative wealth shock, and, with probability $1-\epsilon, \tilde{W}_{1}=W_{1} \geq 0$, which represents the present value of all future income.

The investor can consume, save, or invest in a risky asset (stock) at time 0. The initial stock price $S_{0}$ is normalized to 1 , and the next period stock price is $\tilde{S}_{1}$, where $\tilde{S}_{1}=u>1$ with probability $p>0$, and $\tilde{S}_{1}=d<1$ with probability $1-p$. For simplicity, we assume that the stock price process is independent of the investor's income process and that the interest rate is zero. Then, the investor's problem is to choose consumption $c_{0}$, saving $\alpha$, and stock

\footnotetext{
${ }^{6}$ Extending the insights of Elmendorf and Kimball (2000), our illustrative model in Section 1 of the paper also links background risk to limited participation and shows that no matter how small this background risk is (in the sense that the probability of such a negative wealth shock can be arbitrarily small), it can prevent an investor from investing any amount of cash into risky assets.
} 
investment $\theta$ to solve

$$
\max _{c_{0}, \alpha, \theta} U\left(c_{0}\right)+\delta E\left[U\left(c_{1}\right)\right]
$$

subject to the budget constraints

$$
\begin{gathered}
\alpha=W_{0}-c_{0}-\theta, \\
c_{1}=\alpha+\theta \tilde{S}_{1}+\tilde{W}_{1},
\end{gathered}
$$

where

$$
U(c)= \begin{cases}u(c) & \text { if } c \geq \underline{c} \\ -\infty & \text { otherwise }\end{cases}
$$

where $u(c)$ is strictly increasing and strictly concave for $c \geq \underline{c}, \delta$ is the subjective time discount rate, and $\underline{c}$ is the subsistence level of consumption. ${ }^{7}$

In the above standard set-up, we make the following nonstandard assumption:

Assumption A The magnitude of the negative wealth shock

$$
D=W_{0}-2 \underline{c}>0 .
$$

There are several reasons why such a large negative wealth shock may occur. ${ }^{8}$ For example, a sudden occurrence of long-term disability or diagnosis of a terminal condition can imply significant loss of income and large increase in health expenses. Likewise, unanticipated death of a household's primary income earner can represent a significant shock to income, and in the event of job loss, the required wealth to maintain a minimum standard of living for the uncertain duration of unemployment can often far exceed current wealth (Gruber, 2002).

\footnotetext{
${ }^{7}$ This type of preference is standard in the large literature on habit formation (e.g., Constantinides, 1990, Dybvig, 1995). It essentially assumes that the investor cannot tolerate any consumption below a certain level.

${ }^{8}$ Since $D$ is assumed to be exactly equal to $W_{0}-2 \underline{c}$, it may appear that this assumption is restrictive. However, this assumption is largely for expositional simplicity. First, it is trivial to allow multiple possible negative shock sizes as long as the maximum one is $W_{0}-2 \underline{c}$. Second, if the maximum possible shock exceeds $W_{0}-2 \underline{c}$, then one can replace the negative infinity utility below $\underline{c}$ with a large negative utility and show that the investor will still not participate in the stock market for a wide range of parameter values.
} 
Using this setup, we derive the following result regarding optimal portfolio choice: ${ }^{9}$

Proposition 1 Under Assumption A, the investor does not participate in the stock market, i.e., $\theta^{*}=0$. In addition, the investor only consumes the minimum and saves the rest, i.e., $c_{0}^{*}=\underline{c}$ and $\alpha^{*}=W_{0}-\underline{c}$.

Proposition 1 says that, no matter how small the (positive) probability of a large wealth shock is or how high the expected stock return is, the investor will not participate in the stock market at all, will only consume at the subsistence level today, and will save the rest to hedge against the possible negative wealth shock in the future. Intuitively, since any loss in the stock investment would incur an infinite utility loss if the bad wealth shock occurs, the investor optimally chooses not to participate in the stock market. Increased consumption or decreased saving poses a similar risk. This result holds for a general class of preferences, wealth profiles, and stock market characteristics. It is also consistent with Carroll (2001) who finds that large shocks can have a significant impact on saving and an even greater impact on risky asset investment, despite the small probability of such shocks. ${ }^{10}$

\subsection{Role of Insurance}

While Elmendorf and Kimball (2000) focus on the effects of income taxes in providing implicit insurance, their idea and methodology are applicable to general forms of insurance. Along a similar line of argument, we now demonstrate the effect of insurance on investment, consumption and saving decisions. We assume that the investor can purchase insurance against the

\footnotetext{
${ }^{9}$ All the proofs are presented in the Appendix.

${ }^{10}$ It is worth noting that the nonparticipation and an extremely high saving rate arise no matter how high the investor's wealth is in normal states. As long as the wealth shock in one state of the world is bad enough, even the wealthy people will not participate in the stock market and will save almost all of their wealth for the future. This prediction is consistent with the empirical finding that even wealthy people have a low participation rate (Heaton and Lucas, 1997).
} 
negative wealth shock, and that the insurance premium per dollar coverage is equal to $\lambda \geq 0$. Let $I$ be the dollar amount the investor chooses to insure. Consistent with common insurance practice, we assume that the investor cannot overinsure, i.e.,

$$
I \leq D
$$

With the access to insurance, the investor solves:

$$
\max _{c_{0}, \alpha, \theta, I} U\left(c_{0}\right)+\delta E\left[U\left(c_{1}\right)\right]
$$

subject to (6) and the budget constraints

$$
\begin{gathered}
\alpha=w-c_{0}-\theta-\lambda I \\
c_{1}=\alpha+\theta \tilde{S}_{1}+\tilde{W}_{1}+I 1_{\left\{\tilde{W}_{1}=-D\right\}} .
\end{gathered}
$$

For simplicity, we assume that the insurance premium is fair, i.e., $\lambda=\epsilon$. Then, it can be shown that full insurance is optimal since the cost of insurance will be small relative to the benefit of smoothing consumption across time by consuming more today and investing more in risky stocks. On stock market participation and consumption, we then have

Proposition 2 If the stock has nonzero risk premium, then $\theta^{*} \neq 0$ with access to insurance. In addition, given any $c_{0} \in\left[\underline{c}, W_{0}-\underline{c}\right)$, there exist $\bar{W}_{1}$ and $\underline{\epsilon}$ such that, $\forall W_{1}>\bar{W}_{1}$ and $\epsilon<\underline{\epsilon}$, the optimal time 0 consumption $c_{0}^{*}$ is strictly greater than $c_{0}$.

This proposition suggests that with insurance, as long as the risk premium is nonzero, an investor will optimally participate in the stock market, even when he is poor. This result suggests that developing an insurance market can potentially help improve stock market 
participation and lower risk premium. In practice, insurance coverage and costs vary across products and regions. Proposition 2 implies that the participation rates in the stock market and in the insurance market are positively correlated.

This proposition also implies that access to insurance can significantly increase consumption and reduce saving. For example, if the investor's future wealth is high and the probability of a negative wealth shock is low, then the investor may consume almost all of his initial wealth and save almost nothing when insurance is available. Finally, since participation increases and saving decreases with access to insurance, Proposition 2 predicts a negative correlation between participation and saving rates.

\section{Empirical Analysis}

The model yields a number of testable hypotheses regarding stock market participation rates, saving rates, and insurance coverage. In this section, we test these hypotheses using both cross-country and within-country comparisons. First, we test whether differences in access to private and public insurance across countries and over time are correlated with saving rates and investors' stock holdings. Second, we use U.S. state-level variation in unemployment insurance generosity to test whether unemployment insurance programs are related to observed differences in stock market participation rates across U.S. states. Finally, we test whether U.S. individuals' coverage via an employee-sponsored health, life, or long-term care insurance policy is related to their portfolio choices. 


\subsection{Country-Level Analysis}

\subsubsection{Participation and Insurance}

In our first empirical test, we analyze the correlation between stock market participation levels and the development of private insurance markets across countries. A primary finding of our model is that in the absence of access to low-cost insurance against large, negative wealth shocks, individuals will hold less stocks. Therefore, we should expect to find that in countries with less developed private insurance markets that, all else equal, stock market participation rates should be lower. To test this hypothesis, we run the following cross-country regression:

$$
\text { participation }_{\mathrm{c}}=\beta_{0}+\beta_{1} \text { insurance }_{\mathrm{c}}+\gamma \mathrm{X}_{\mathrm{c}}+\varepsilon_{\mathrm{c}}
$$

where participation is the share of individuals in country $c$ that participate in the domestic stock market via direct stock holdings. We obtain our measure of participation from Giannetti and Koskinen (forthcoming), which constructed country-level participation rates for 26 countries based on surveys conducted between 1997-2000. ${ }^{11}$ The variable insurance measures the degree of private insurance in country $c$. This is measured using the ratio of life and non-life insurance premiums to GDP in 1995 as reported in the financial structure database produced by the World Bank and described in Beck, Demirguc-Kunt, and Levine (1999). A larger insurance value would indicate a relatively more developed private insurance market in that country. ${ }^{12}$ Finally, $X_{c}$ includes a variety of country-level controls discussed below in more detail, and because of our small sample size, we bootstrap the standard errors to ensure that we do not overstate the statistical significance of our findings (Horowitz, 2001). The

\footnotetext{
${ }^{11}$ See Giannetti and Koskinen (forthcoming) for more details about exactly how the participation rates were calculated and the various dates at which the surveys were conducted. This data was also used by Guiso, Sapienza, and Zingales (2008).

${ }^{12} \mathrm{All}$ results are robust to measuring insurance penetration in other years or to instead using an average of insurance penetration in previous years.
} 
estimates from this regression are reported in Table 1.

Consistent with our model's implications, we find a strong positive correlation between stock market participation rates and private insurance penetration. The univariate regression results reported in Column (1) of Table 1 show a strong and statistically significant relation private insurance markets and stock market participation levels, and the magnitude of the correlation is economically significant. An increase in a country's extent of private insurance by one standard deviation is associated with a seven percentage point increase in the country's participation rate.

In Figure 1, we provide a scatter plot of the data to demonstrate that the positive correlation between participation rates and private insurance is quite robust and not driven by outliers. Moreover, there is no evidence that the findings are driven by a particular type of insurance. Though not reported here, we find that the strong positive correlation is statistically significant for both life and non-life insurance. Therefore, in subsequent analysis, we will continue to use the combination of life and non-life insurance premiums over GDP to better capture the overall development of a country's private insurance market. ${ }^{13}$

Our model also suggests that government safety nets, such as unemployment insurance, disability insurance, and publicly funded social security programs, should have an impact on household portfolio choices. By eliminating the possibility of suffering from a large, negative shock to income, these programs may induce individuals to increase their holdings of risky stocks and reduce their overall saving rate.

To test this hypothesis, we replace our measure of private insurance with the percentage of individuals in the country that are covered by a government-funded social security program.

\footnotetext{
${ }^{13} \mathrm{~A}$ priori it is unclear which measure of insurance might better capture an individual's ability to insure against large, adverse wealth shocks. Life insurance will play an important role in insuring households against the death of the primary income earner in the household, while non-life insurance products such as health, automobile, and home insurance, could provide valuable protections against other adverse income shocks.
} 
By providing a base amount of income for individuals in retirement, a social security program implicitly insures individuals against large adverse shocks to their pre-retirement income. We acquire information about a country's social security program through the World Bank's IEC database, which reports the fraction of a country's working age population covered by a social security program. The dataset covers 86 countries over the years 1975-1994, though the coverage for most countries is limited to just two or three observations between the years 1987-1993. For the 14 countries that have both stock market participation and social security coverage data available, we calculate a country's average social security coverage rate reported by the World Bank's IEC data.

The estimates suggest a very strong positive correlation between social security coverage and stock market participation rates in a country. As shown in Column (2) of Table 1, we find that an increase in a country's social security coverage by one percentage point is associated with a stock market participation rate that is 0.29 percentage points larger.

One weakness of the cross-country comparisons, however, is that the correlation between insurance and stock market participation levels may be driven by omitted factors and not necessarily capture a causal relationship. For example, countries with greater economic or financial development may have both higher participation rates and greater private insurance penetration. Moreover, a number of recent papers have demonstrated the potential importance of shareholder rights, legal origin, and trust for stock market participation rates, and if these factors are also related to the development of insurance markets, there will be an omitted variable bias. To address this concern, a variety of controls are added to the base specification for private insurance, and these results are reported in Columns (3)-(7) of Table 1.

Further supporting the potential role of insurance markets, the strong positive correlation between stock market participation rates and private insurance continues to hold even after controlling for a country's level of financial development. This is shown in Column (3), where 
we control for financial development using the total stock market capitalization normalized by GDP. The strong positive correlation between participation rates and private insurance is unchanged, and surprisingly, there is no evidence that financial development is related to stock market participation rates. ${ }^{14}$

The strong, positive correlation between stock market participation rates and private insurance continues to hold even after controlling for a number of other country-level factors that have been demonstrated to be important factors in stock market participation levels. In Column (4), of Table 1, we control for the level of investor protection using shareholder rights, which is measured using the anti-director rights index constructed by La Porta, Lopezde-Silanes, Shleifer, and Vishny (1998). Similar to Giannetti and Koskinen (forthcoming), we find that shareholder rights is positively related to participation levels, and the correlation between insurance penetration and participation rates only declines by $14 \%$ compared to the unconditional correlation reported in Column (1). ${ }^{15}$ This suggests that private insurance penetration is positively correlated with participation rates even after controlling for shareholder rights.

In Column (5), we control for the fraction of individuals in a country that reply that 'most people can be trusted' in the World Values Survey, 1995-1999. Guiso, Sapienza, and Zingales (2008) argue that individuals' trust of others is positively related to their willingness to hold stocks, and our estimates confirm their findings. However, insurance penetration still remains a strong predictor of country-level participation rates, and the correlation only declines by

\footnotetext{
${ }^{14}$ In an unreported test, we also tried controlling for financial development using the stock market turnover ratio and the value of shares traded normalized by GDP. Again, the correlation between insurance penetration and participation rates remains largely unchanged, and there is little evidence that financial development is related to participation rates.

${ }^{15}$ Kimball, Sahm, and Shapiro (2008) show that correcting for measurement error can magnify the effect of controls measured with error. Therefore, when controls are proxies measured with error as here, it is important to also demonstrate that the addition of controls does not change the coefficients substantially. The magnitude of the unconditional correlation reported in Column (1) of Table 1 would, however, need to decline by approximately $64 \%$ in order for the coefficient to become no longer statistically significant at the $10 \%$ significance level.
} 
$19 \%$ relative to the unconditional correlation reported in Column (1). Similarly, the inclusion of controls for legal origin [Column (6)], as captured by an indicator for common law origin, also does not alter the findings. Finally, simultaneous inclusion of all controls [Column (7)] does not affect the findings. Insurance remains a strong, positive predictor of stock market participation levels. In unreported regressions, the positive correlation between social security coverage and participation rates, as reported in Column (2) of Table 1, also remains largely unchanged with the inclusion of additional controls. ${ }^{16}$

\subsubsection{Insurance and Saving Rates}

While the strong correlation of stock market participation rates with measures of private and public insurance coverage supports our argument that insurance may play a crucial role in explaining participation rates, there is still a possibility that the findings could be driven by other country-level determinants not controlled for in these regressions. One potential way to address this concern would be to use variation in the development of insurance markets and stock market participation levels over time along with country-level fixed effects, but unfortunately, the lack of data on stock market participation over time makes this type of analysis infeasible.

The model, however, does suggest another important implication pertaining to saving rates that yields more easily itself to such a test. Specifically, the model suggests that less-developed countries may better achieve their goal of decreasing their private saving rate and increasing consumption by developing their private insurance industry. Since there exist savings data and insurance penetration data for a number of countries over time, it is possible to conduct

\footnotetext{
${ }^{16}$ In unreported regressions, we also tried controlling for economic development, using the log of GDP per capita in 1995. Again, the correlation between private insurance and participation rates remains largely unchanged, while economic development was not significantly related to participation rates. Additionally, controlling for the fraction of of a country's shares that are 'closely held', as measured by Dahlquist, Pinkowitz, Stulz, and Williamson (2003), does not alter the findings.
} 
a more rigorous test of this prediction that eliminates time-invariant determinants via the inclusion of country-level fixed effects. To test this second hypothesis, we run the following country-level, fixed effects specification:

$$
\text { saving } \text { rate }_{\mathrm{c}, \mathrm{t}}=\beta_{0}+\beta_{1} \text { insurance }_{\mathrm{c}, \mathrm{t}}+\alpha_{\mathrm{c}}+\delta_{\mathrm{t}}+\varepsilon_{\mathrm{c}, \mathrm{t}} \text {, }
$$

where saving rate is the private saving rate of country $c$ in year $t$ and insurance is the ratio of private insurance premiums to GDP. For our measure of savings, we rely on the World Savings Database, which measures a country's private saving rate as the difference between gross national saving and public sector saving normalized by gross national disposable income. ${ }^{17}$ This data goes back as early as 1960 for some countries and ends in 1995. For our measure of insurance, we again use the World Bank's Financial Structure database, which measures total life and non-life insurance premiums over GDP beginning in 1987. After combining the two datasets on saving rates and insurance premiums, we are left with a panel of 49 countries that report both variables, and these observations range between the years of 1987-1995.

Since this regression includes country-level fixed effects, the parameter of interest, $\beta_{1}$, will only be estimated using within-country variation in the saving rate over time, and will capture how an increase in insurance penetration at the country-level is correlated with changes in the private saving rate within that country. The inclusion of country fixed effects will exclude the possibility that the findings are driven by time invariant differences in institutions, legal origin, etc. To control for the possibility of a global trend in savings and insurance penetration during our sample time period, we also include year dummies, $\delta_{t}$. The estimates, with standard errors clustered at the country level, are reported in Table 2.

The estimates strongly support the hypothesis that greater access to private insurance

\footnotetext{
${ }^{17}$ Public sector savings is defined as the savings by the central, state, local, and regional governments plus state-owned enterprises and other non-financial public enterprises. See the World Savings Database help file for Module 3A, Revision 3.00 on how this measure is constructed.
} 
reduces the saving rate of individuals. Using the entire sample of countries, we find that an increase in private insurance penetration is strongly and negatively correlated with the overall saving rate, as reported in Column (1) of Table 2. The finding holds even after controlling for GDP per capita and overall financial development, as shown in Columns (2) and (3). ${ }^{18}$ While GDP per capita is not strongly correlated with saving rates, there is a strong, negative correlation between financial development and saving rates. This is consistent with financial development providing individuals greater ability to transfer resources across time so as to smooth consumption and reduce their need for precautionary savings.

A greater level of public insurance, as captured by a country's fraction of public expenditures on social security (as reported by the World Bank's IEC database), is also negatively correlated with private savings rates. This is seen in Column (4) of Table 2. The magnitude of the coefficient indicates that a one standard deviation increase in the fraction of public expenditures for social security is associated with a decrease of thirteen percentage points in the country's private saving rate.

The model also suggests that the negative relation between insurance availability and saving rates should be particularly acute when individuals are more likely to experience income shocks that put them below a 'subsistence' level. Therefore, we might expect to find the negative relation between insurance and saving rates to be particularly strong in less-developed countries where such shocks are likely more common. The evidence appears to support this hypothesis. When we split the sample into less- and more-developed countries, we find that the negative correlation between private insurance penetration and saving rates is predominately driven by developing countries. This is seen in Columns (5) and (6) where we divide the sample between "Low Income" and "High Income" countries. ${ }^{19}$ While the correlation between saving

\footnotetext{
${ }^{18}$ In Table 2, we again control for financial development using the ratio of stock market capitalization to GDP. All of the results are also robust to using a variety of other controls including the ratio of financial deposits to GDP, the value of shares traded over GDP, and the stock market's turnover rate.

${ }^{19}$ Countries are classified as 'Low Income' if the financial structure database lists their income group as
} 
rates and insurance penetration is negative in both samples, it is only statistically significant among the less-developed countries. In unreported results, we also find suggestive evidence that the negative correlation between public insurance, as captured by social security expenses, and private savings rates is larger in less-developed countries. ${ }^{20}$

\subsubsection{Participation and Saving Rates}

Another implication of our theory is that high saving rates should be associated with low participation rates. $^{21}$ This negative correlation between saving rates and participation rates runs counter to theories based primarily on fixed participation costs. If fixed costs were the primary driver of low participation rates, a high saving rate would likely generate a larger fraction of people with enough wealth to justify participation, which would instead imply a positive correlation.

To analyze the correlation between participation and savings rates, we now regress countrylevel participation rates on private savings rates. In particular, we estimate the following cross-country regression:

$$
\text { participation }_{\mathrm{c}}=\beta_{0}+\beta_{1} \text { saving } \text { rate }_{\mathrm{c}}+\gamma \mathrm{X}_{\mathrm{c}}+\varepsilon_{\mathrm{c}}
$$

where participation is the share of individuals in country $c$ that participate in the domestic stock market via direct stock holdings as defined earlier, and saving rate is the average private saving rate of country $c$ from 1990-1995 calculated using the World Savings Database. We again bootstrap the standard errors to reduce the likelihood of overstating the statistical either 'Lower Income' or 'Lower Middle Income', and as 'High Income' otherwise.

${ }^{20}$ This stronger correlation in low-income countries suggests the negative correlation between social security expenses and savings rates shown earlier is not driven entirely by social security acting as a direct substitute for personal savings by individuals.

${ }^{21}$ We thank our anonymous referee for pointing out this result and suggesting the following tests. 
significance of our estimates, which are reported in Table 3.

As suggested by our theory, the univariate correlation between participation rates and saving rates is negative and statistically significant. This is seen in Column (1) of Table 3. The economic significance is large as well. The estimated coefficient indicates that an increase

in a country's average private saving rate by one standard deviation is associated with a half standard deviation reduction in a country's participation rate. The evidence is inconsistent with theories based primarily on fixed participation costs.

The negative relationship between participation and saving rates is also quite robust and not driven by outliers, as shown in Figure 2. Including controls for income, as captured by GDP per capita, and financial development do not affect the magnitude of the relationship. This is seen in Columns (2) and (3) of Table 3.

\subsection{Participation and Unemployment Insurance in the U.S.}

Overall, the country-level analysis demonstrates that access to insurance correlates positively with stock market participation and negatively with saving rates. However, as noted above, there is the possibility that the availability of insurance may differ across countries in a systematic way that biases our estimates. While it is encouraging that the estimates remain strongly significant even after controlling for numerous country-level factors and after using only within-country variation over time, it would be helpful to demonstrate that the importance of insurance still holds for a more uniform set of economies and at the household level.

To this effect, differences in unemployment insurance premiums across U.S. states provide a potentially interesting test of our model that suffers less from these concerns. As noted by Gruber (1994) and Chetty (2008), the degree to which unemployed individuals' wages are replaced varies significantly across U.S. states. Given this, our model would suggest that, all 
else equal, in those states with greater unemployment insurance generosity, fewer individuals will be subject to income shocks that drop them below their subsistence level, and hence, average stock market participation levels should be higher. Additionally, while there are certainly differences in household characteristics and local governments across U.S. states, it seems reasonable to expect that these differences will be less than those of our country-level analysis, and the greater availability of data at both the household and state level within the U.S. allows us to better control for these differences.

To test the hypothesis that greater unemployment insurance generosity should increase stock market participation levels, we run the following regression:

$$
\text { participation }_{\mathrm{s}, 1992}=\beta_{0}+\beta_{1} \mathrm{UIG}_{\mathrm{s}, 1992}+\varepsilon_{\mathrm{s}} \text {, }
$$

where participation is the fraction of households in state $s$ that owned stocks in 1992, as determined by the Health and Retirement Study (HRS) in 1992 and reported by Hong, Kubik, and Stein (2004). ${ }^{22}$ UIG is our measure of the 'unemployment insurance generosity' for each state. This is measured using the log value of average weekly unemployment benefits paid to individuals in state $s$ in 1992, as reported by the U.S. Department of Labor. ${ }^{23}$ A higher $U I G$ indicates that a state's unemployment insurance program provides relatively higher wages to individuals that are unemployed. As before, we use bootstrapped standard errors.

In support of our model, we find a strong positive relationship between average stock market participation levels and unemployment insurance generosity across U.S. states [Table 4, Column (1)]. This finding is important for two reasons. First, it again demonstrates that social

\footnotetext{
${ }^{22}$ As noted by Hong, et al (2004), the HRS survey question they use to calculate whether households hold stocks does not include holdings in retirement funds, and therefore, likely understates the true participation rate.

${ }^{23}$ These average weekly benefits were calculated by Chetty (2008) and downloaded from the author's website. Our later regression results are also similar when we use unemployment insurance generosity as measured in other years and when we directly use weekly benefits rather than logged values.
} 
insurance programs may play an important role in determining stock market participation levels. Second, it shows that the strong positive relationship between participation levels and insurance coverage observed in the country-level data also exists within the U.S. This within country evidence mitigates the potential concern of omitted factors, such as legal origin and financial development, that was present in the country-level analysis.

However, there could still be an endogeneity problem if differences in U.S. household characteristics across states is correlated with unemployment insurance generosity. To address this, we rerun the above regression using the abnormal participation rate constructed by Hong, Kubik, and Stein (2004). This state-level measure captures the residuals from a householdlevel regression of a stock market participation indicator onto household characteristics such as age, income, wealth, years of education, race, risk tolerance, and an urban versus rural indicator. ${ }^{24}$ In other words, this variable captures the amount of each state's average participation rate that cannot be explained by characteristics of the household. By using this as our dependent variable instead, we are better able to exclude the possibility that omitted factors at the household level may drive the relationship between unemployment insurance generosity and stock market participation rates across U.S. states.

The estimates from this test, as reported in Column (2) of Table 4, indicate the positive relationship between state-level participation rates and unemployment insurance levels is not driven mainly by differences in household characteristics across states. While using the residuals from the household regression weakens the estimate slightly, we still find a positive relation between UIG and stock market participation levels that is significant at the $10 \%$ level, and the relationship is robust to outliers, as seen in Figure 3.

While the significant relationship between state-level unemployment generosity and participation rates, even after controlling for households characteristics, is highly suggestive of

\footnotetext{
${ }^{24}$ See Hong, Kubik, and Stein (2004) for more details on how this measure was constructed.
} 
a role for public safety nets, there is still a potential concern that state-level unemployment generosity may be correlated with a state's overall level of economic development or education levels, which may in turn be directly related to participation rates. If this were true, we could be wrongly attributing the impact of overall economic development or education to unemployment generosity.

However, the positive relationship between state-level unemployment generosity and participation rates does not appear driven by the differing levels of development or education across U.S. states. In Column (3), we add a control for the percentage of persons within the state with some college education, and in Column (4), we add a control for the log(average household income) of the state. Both controls are calculated using the 1990 U.S. Census. Even after adding these controls, the relationship between participation levels and unemployment insurance generosity remains largely unchanged in magnitude and statistically significant.

Similar to our country-level analysis, we should also expect to find that the importance of insurance for stock market participation should be greater if individuals face greater exposure to large, adverse shocks to their income. In this case, the impact of unemployment insurance should be particularly large in states where a greater fraction of workers are at risk of losing their job. This is in fact what we observe in the data. This is shown in Table 5 where we repeat our analysis, but now include a control for the risk of a states' population and the interaction of this term with the unemployment generosity of that state. Our measure of risk is an indicator equal to 1 for states with an above median fraction of workers in 1992 that are located in 2-digit SIC industries that have seen drops in overall employees in the previous five years. This measure is calculated by using the 1987-1992 annual data reported by the U.S. Census Bureau in its County Business Patterns database. To make the interpretation of our coefficients easier to interpret, we have demeaned $U I G$.

As shown in Column (1) of Table 5, the positive relationship between the generosity of 
a state's unemployment insurance program and stock market participation levels is driven by states where a large fraction of workers are employed in industries exhibiting significant drops in employment in the past five years. These results are also robust to including controls for percentage of the states' population with at least some college education and the average household income of the state, as seen in Columns (2) and (3). Moreover, it is important to reemphasize that the dependent variable, abnormal stock market partcipation, is the statelevel residual from a household-level regression of a stock market participation indicator onto household characteristics. Therefore, the positive impact of unemployment generosity reported in Column (3) is above and beyond what can be explained by household characteristics and state-level measures of education and wealth.

\subsection{U.S. Household Participation and Health Insurance}

In addition to potential unemployment, individuals may also suffer a large, negative wealth shock following an adverse health shock. Given this, our model also indicates that individuals should be more likely to participate in the stock market when they are insured against such health shocks. This will be more likely true when individuals are covered under an employersponsored health insurance program. Households may also purchase life or long-term care insurance policies to mitigate such shocks. To that effect, we should expect to find households covered by such insurance policies to be more likely to hold risky stocks.

To test this hypothesis, we estimate the following household regression using Probit:

$$
\text { participation }_{\mathrm{h}}=\beta_{0}+\beta_{1} \text { insurance }_{\mathrm{h}}+\gamma \mathrm{X}_{\mathrm{h}}+\varepsilon_{\mathrm{s}},
$$

where participation is an indicator that equals one if the household reports owning stocks in the Health and Retirement Study (HRS) of 1992. Insurance includes a number of indicators 
for whether the household reports being covered by an employer-sponsored health insurance program, life insurance policy, or long-term care policy. Finally, $X_{h}$ captures a variety of other household characteristics that may affect stock market participation levels such as age, wealth, and income. In particular, we include the variables Age, which is the age of the oldest member in the household, and Education, which is the largest number of years of education obtained by a household member. We also include logged values of the households' reported wealth (including property) and income and indicators Race and Marriage that equal one if the household reports any non-white members or marriage. The marginal effects from this Probit regression are reported in Table $6 .{ }^{25}$

As predicted by the model, we find a strong positive relationship between stock market participation and insurance against adverse health shocks. All three types of insurance employee-sponsored health insurance, life insurance, and long-term care insurance - exhibit a strong, positive relationship with stock market participation for U.S. households even after controlling for household income, wealth, and education. The magnitudes are economically significant. As reported in Column (4), households covered under an employee-sponsored health insurance program are ten percentage points more likely to own risky stocks. This finding is consistent with the recent empirical findings of Qiu (2006) that households with health insurance are more likely to own stocks and tend to invest a larger proportion of their financial assets in stocks than uninsured households do, and of Goldman and Maestas (2005), who find that better health insurance is associated with greater investments in risky assets.

These results are also unlikely driven by variation in risk aversion across households or a positive correlation between employee-sponsored retirement saving plans and health insurance. Variation in risk aversion across individuals would yield the opposite correlation, with high risk aversion leading to more health insurance and less stock holding. And, the stock-holding

\footnotetext{
${ }^{25}$ The findings in Table 6 are also robust to using an OLS or Logit specification.
} 
variable used in this analysis is stock-holding outside of employee-sponsored retirement saving plans, so a positive correlation between stock-holding and health insurance cannot be explained by a correlation in employers offering both health insurance and 401(k)'s.

These results, however, should be still interpreted with caution. While the positive relationship between participation rates and employee-sponsored health insurance is suggestive, a potential endogeneity concern remains. For example, there is some chance that a positive correlation between holding health insurance and stock holding could be induced by variations in financial sophistication across individuals, since both health insurance and stock holding may be fostered by financial sophistication.

\section{Concluding Remarks}

Our empirical analysis finds broad support for the idea that access to insurance is related to households' investment and savings decisions. We find that the development of private insurance markets is positively correlated to stock market participation levels and negatively correlated with savings rates. The degree to which individuals' retirement consumption is insured via a government-funded social security program is also positively related to stock holdings and negatively related to their overall saving rates. These findings are particularly strong in low-income countries where the risk of adverse income shocks is likely more acute. There is also household-level evidence that differences in the generosity of unemployment insurance across U.S. states are correlated with households' stock market participation rates, particularly in states where workers are at a greater risk of losing their jobs. This holds even after controlling for both household characteristics and state-level differences in income and education levels. The use of health, life, and long-term care insurance is also positively related to U.S. household participation rates. 
While each of these tests admittedly has its weaknesses, the combination of empirical evidence and the simplicity of our model suggest a potentially important role of insurance for explaining both the limited stock market participation and the low-consumption-high-savings puzzles. Our two primary findings, that better insurance access is negatively related to saving and positively related to risky asset holding, is also not easily explained by other models. Since savings leads to higher wealth, which in itself should tend to raise risky asset holding, saving and risky asset holding would not generally move in opposite directions. Elmendorf and Kimball (2000), however, suggests that uninsured background risk does exactly this: raise saving and lower risky asset holding. To our knowledge, this empirical relation between insurance and household investment and savings decisions has not been documented before.

Our findings suggest that the growth of a private insurance industry or the provision of government funded social safety nets, such as universal health care, may affect participation rates and domestic consumption. In particular, the dramatic growth of private insurance markets may play a role in explaining reduced savings and increased consumption in many developed countries, including the U.S.. At the same time, the findings indicate that a sudden collapse of the private insurance market (or confidence in contracts that provide insurance to investors) may induce a sharp drop in consumption and a flight to risk-free forms of savings. Such a shift in household portfolios could have implications for the broader economy beyond that of the initial collapse of insurance markets.

The findings also have many implications for developing countries that often exhibit high saving rates and low consumption. Combined, high savings and low consumption increase their dependence on foreign demand for economic growth. To mitigate this dependence, many developing countries adopt various policies attempting to stimulate consumption and lower the domestic saving rate. For example, the Chinese government in recent years lowered its interest rates substantially to dissuade people from saving. Our model suggests that the 
development of private insurance markets may provide another mechanism through which governments can reduce domestic savings. Moreover, the development of social safety nets may also promote consumption and stock market participation.

Overall, there is little research devoted to the impact of insurance on consumption, saving, stock market participation, and asset pricing, and our model suggests that the interactions among insurance, consumption, saving, and portfolio choice may provide a new and promising line of research. 


\section{References}

Ang, A., G. Bekaert, J. Liu, 2005. Why stocks may disappoint? Journal of Financial Economics 76, 471-508.

Basak, S., D. Cuoco, 1998. An equilibrium model with restricted stock market participation. The Review of Financial Studies 11, 309-341.

Beck, T., A. Demirguc-Kunt, R. Levine, 2000. A new database on the structure and development of the financial sector. World Bank Economic Review, 14(3), 597-605.

Campbell, J.Y., 2006. Household finance. The Journal of Finance 61, 1553-1604.

Cao, H., T. Wang, H. H. Zhang, 2005. Model uncertainty, limited market participation, and asset prices. The Review of Financial Studies 18, 1219-1251.

Cao, S.L., and F. Modigliani, 2004. The Chinese saving puzzle and the life-cycle hypothesis. Journal of Economic Literature 42, 145-170.

Carroll, C. D., 2001, Theory of the consumption function, with and without liquidity constraints. Journal of Economic Perspectives 15, 23-46 .

Carroll, C. D., M. Kimball, 2008. Precautionary saving and precautionary wealth. The New Palgrave Dictionary of Economics.

Carroll, C. D., J. R. Overland, D. N. Weil, 2000. Saving and growth with habit formation. American Economic Review 90, 341-355.

Carroll, C. D., J. R. Overland, D. N. Weil, 1997, Comparison utility in a growth model. Journal of Economic Growth 2, 339-367.

Carroll, C. D., D. N. Weil, 1994, Saving and growth: A reinterpretation. Carnegie-Rochester Conference Series on Public Policy 40, 133-192. 
Chamon, M., E. Prasad, 2006. The determinants of household saving in China. International Monetary Fund Working Paper.

Chetty, R., 2008. Moral hazard vs. liquidity in unemployment insurance. Journal of Political Economy 116, 173-234.

Chou, S. Y., J. T. Liu, J. K. Hammitt, 2003. National health insurance and precautionary saving: Evidence from Taiwan. Journal of Public Economics 87, 1873-1894.

Constantinides, G. M., 1990. Habit formation: A resolution of the equity premium puzzle, Journal of Political Economy 98, 519-543.

Dahlquist, M., L. Pinkowitz, R. M. Stulz, R. Williamson, 2003. Corporate governance and home bias. Journal of Financial and Quantitative Analysis 38, 87-110.

Dow, J., S. Werlang, 1992. Uncertainty aversion, risk aversion and the optimal choice of portfolio. Econometrica 60, 197-204.

Dybvig, P. H., 1995. Duesenberry's racheting of consumption: Optimal dynamic allocation and investment given intolerance for any decline in standard of living. The Review of Economic Studies 62, 287-313.

Eeckhoudt, L., M. Kimball, 1992. Background risk, prudence and insurance demand. G. Dionne (ed.) Contributions to Insurance Economics, Kluwer Academic Press, 239-254.

Elmendorf, E., M. Kimball, 2000. Taxation of labor income and the demand for risky assets. International Economic Review 41, 801-832.

Epstein, L., M. Schneider, 2007. Learning under ambiguity. The Review of Economic Studies 74, 1275-1303. 
Giannetti, M., Y. Koskinen. Forthcoming. Investor protection, equity returns, and financial globalization. Journal of Financial and Quantitative Analysis.

Goldman, D., N. Maestas, 2005. Medical expenditure risk and household portfolio choice. NBER working paper, 11818.

Gruber, J., 1994. The consumption smoothing benefits of unemployment insurance. American Economic Review 87, 192-203.

Gruber, J., 2002. The wealth of the unemployed. Industrial and Labor Relations Review 55, 79-94.

Gruber, J., A. Yelowitz, 1999. Public health insurance and private savings. Journal of Political Economy 107, 1249-1274.

Guiso, L., M. Haliassos, T. Jappelli, 2003. Household stockholding in Europe: Where do we stand and where do we go? Economic Policy 18, 117-164.

Guiso, L., T. Jappelli, D. Terlizzese, 1996. Income risk, borrowing constraints and portfolio Choice. American Economic Review 86, 158-72.

Guiso, L., P. Sapienza, L. Zingales, 2008. Trusting the stock market. Journal of Finance 63, 2558-2600.

Haliassos, M., C. C. Bertaut, 1995. Why do so few hold stocks? Economic Journal 105, $1110-1129$.

Heaton, J., D. Lucas, 1997. Market frictions, savings behavior and portfolio choice. Macroeconomic Dynamics 1, 76-101.

Heaton, J., D. Lucas, 2000. Portfolio choice and asset prices: The importance of entrepreneurial risk. Journal of Finance 55, 1163-1198. 
Hong, H., J. D. Kubik, J. Stein, 2004. Social interaction and stock-market participation. Journal of Finance 59, 137-163.

Horowitz, J. L., 2001. The Bootstrap. Handbook of econometrics, eds. James J. Heckman and Edward Leamer, New York: Elsevier Science, Volume 5, 3159-3228.

Huang, J., J. Wang, 2007. Market liquidity, asset prices, and welfare. MIT Working Paper.

Kimball, M., 1993. Standard risk aversion. Econometrica 60, 589-611.

Kimball, M., 1992. Precautionary motives for holding assets. The New Palgrave Dictionary of Money and Finance, Peter Newman, Murray Milgate and John Eatwell (eds.), Stockton Press, New York, 158-161.

Kimball, M., C. Sahm, M. Shapiro, 2008. Imputing risk tolerance from survey responses. Journal of the American Statistical Association: Applications 103, 1028-1038.

La Porta, R., F. Lopez-de-Silanes, A. Shleifer, and R. W. Vishny, 1998. Law and finance. Journal of Political Economy 106, 1113-1155.

Linnainmaa, J., 2005. Learning and stock market participation. University of Chicago GSB Working Paper.

Mankiw, N. G., S. P. Zeldes, 1991. The consumption of stockholders and nonstockholders. Journal of Financial Economics 29, 97-112.

Polkovnichenko, V., 2007. Life cycle portfolio choice with additive habit formation preferences and uninsurable labor income risk. The Review of Financial Studies 20, 83-124

Vissing-Jorgensen, A., 2002. Towards an explanation of household portfolio choice heterogeneity: Nonfinancial income and participation cost structures. NBER Working Paper. 


\section{Appendix}

In this appendix, we provide all the proofs.

Proof of Proposition 1. The investor's problem can be written as

$$
\begin{aligned}
& \max _{c_{0}, \theta} \quad U\left(c_{0}\right)+\delta\left[p(1-\epsilon) U\left(W_{0}-c_{0}-\theta+\theta u+W_{1}\right)\right. \\
&+(1-p)(1-\epsilon) U\left(W_{0}-c_{0}-\theta+\theta d+W_{1}\right) \\
&+p \epsilon U\left(W_{0}-c_{0}-\theta+\theta u-D\right) \\
&\left.+(1-p) \epsilon U\left(W_{0}-c_{0}-\theta+\theta d-D\right)\right] .
\end{aligned}
$$

Suppose $\theta>0$, then we have

$$
\begin{aligned}
W_{0}-c_{0}-\theta+\theta d-D & \leq W_{0}-c_{0}-\theta+\theta d-\left(W_{0}-2 \underline{c}\right) \\
& \leq \underline{c}-\theta+\theta d \\
& <\underline{c} .
\end{aligned}
$$

So the fourth term in (14) is $-\infty$ and other terms less than $+\infty$. Therefore, we must have $\alpha^{*} \leq 0$. Similar argument on the third term leads to the conclusion that $\alpha^{*} \geq 0$. Thus we must have $\theta^{*}=0$. Given that $\alpha^{*}=0$, and $U(c)=-\infty$ for any $c<\underline{c}$, we must have $c_{0}^{*}=\underline{c}$.

Proof of Proposition 2. Taking the first derivative of the objective function in (14) with respect to $\theta$ and evaluating it at $\epsilon=0$, we have

$$
(p u+(1-p) d-1)\left[U^{\prime}\left(W_{0}-c_{0}-\lambda I+W_{1}\right)+U^{\prime}\left(W_{0}-c_{0}-\lambda I+I-D\right)\right],
$$


which is always positive (negative) if $(p u+(1-p) d-1)>(<) 0$ for any optimal choice of $c_{0}=c_{0}^{*}$ and $I=I^{*}$, since the utility function is strictly increasing. This implies that $\theta^{*} \neq 0$ as long as the risk premium $(p u+(1-p) d-1)$ is not zero (recall that we set interest rate to zero for notational simplicity).

As $W_{1}$ approaches $\infty$ and $\epsilon$ approaches 0 , the first derivative of the objective function in (14) with respect to $c_{0}$ approaches $U^{\prime}\left(c_{0}\right)>0$. This implies that $c_{0}^{*}$ must approach $W_{0}-\underline{c}$ and hence greater than any $c_{0}<W_{0}-\underline{c}$. 


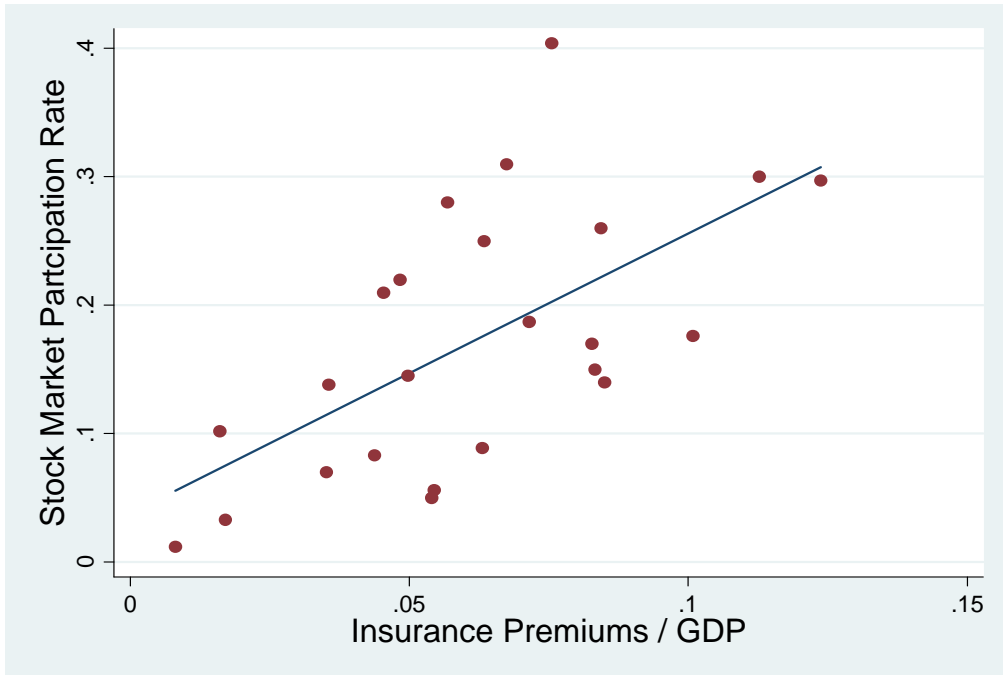

\section{Figure 1: Stock Market Participation Rates and Insurance}

This figure displays the univariate scatter plot of stock market participation rates across countries and the ratio of insurance premiums to GDP in 1995. Participation rates are constructed using country-level surveys conducted between 1997-2000 as reported in Giannetti and Koskinen (2007). The ratio of insurance premiums to GDP is obtained from the financial structure database produced by the World Bank and described in Beck, Demirguc-Kunt, and Levine (1999). The line represents the fitted estimates obtained from the univariate regression.

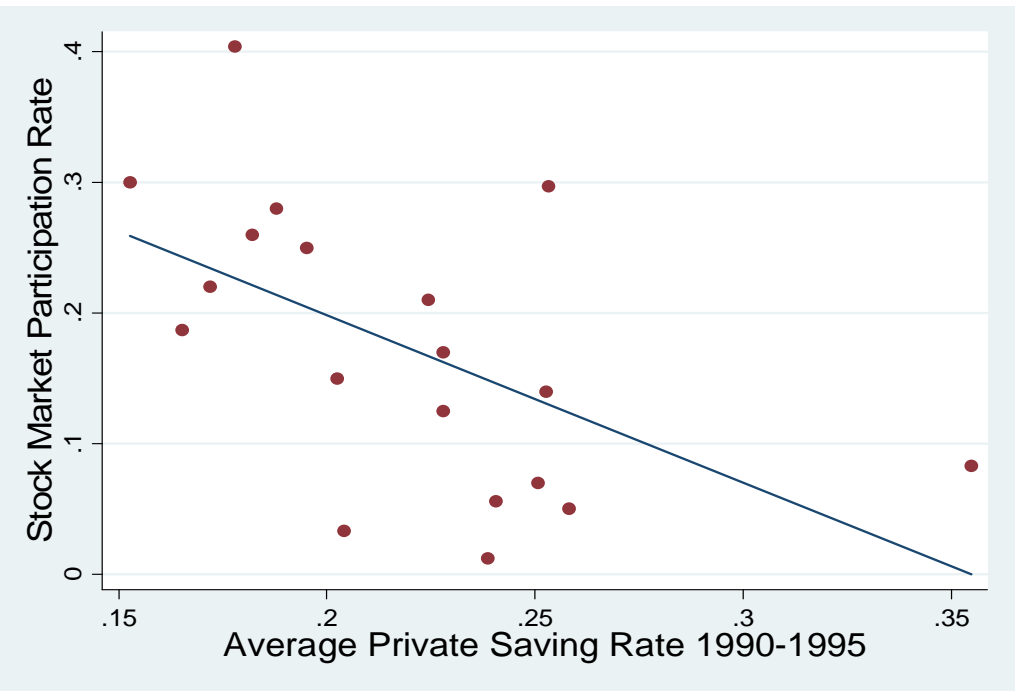

\section{Figure 2: Participation Rates and Saving Rates}

This figure displays the univariate scatter plot of stock market participation rates across countries and the average private saving rates from 1990-1995. Participation rates are constructed using country-level surveys conducted between 1997-2000 as reported in Giannetti and Koskinen (2007). The private saving rate is constructed using the ratio of private saving to gross national disposable income reported by the World Savings Database, where private savings represents the difference between gross national savings and public sector savings. The line represents the fitted estimates obtained from the univariate regression. 


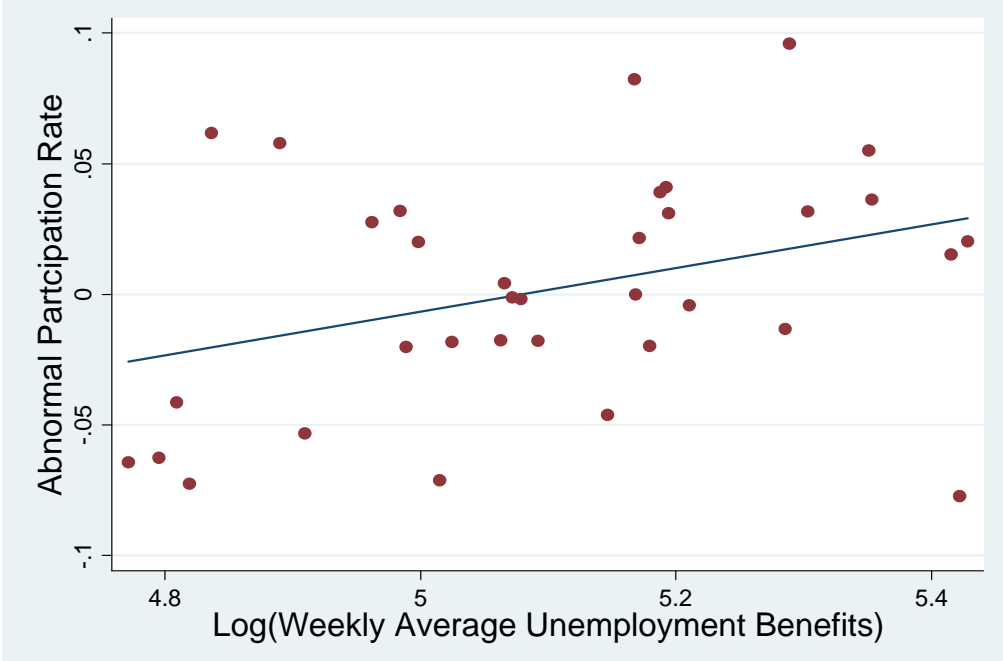

Figure 3: Participation and Unemployment Insurance

This figure plots the univariate scatter plot of abnormal stock market participation rates across U.S. states and generosity of unemployment insurance in 1992. Abnormal participation rates are the state-level residuals from a household-level regression of a stock market participation indicator onto household characteristics. These residuals were obtained from Hong, Kubik, and Stein (2004). Unemployment insurance generosity is captured using $\log$ (average amount of weekly unemployment benefits paid to individuals in a state), as reported by the U.S.

Department of Labor. These weekly benefit averages were obtained from Chetty (2008). 


\section{Table 1}

\section{Stock Market Participation and Insurance}

\section{Dependent Variable $=$ Stock Market Participation Rate}

\begin{tabular}{llllllll} 
& \multicolumn{1}{c}{$(1)$} & $(2)$ & $(3)$ & $(4)$ & $(5)$ & $(6)$ & \multicolumn{1}{c}{$(7)$} \\
\cline { 2 - 7 } Private Insurance & $\begin{array}{l}2.18^{* * *} \\
(0.42)\end{array}$ & & $\begin{array}{l}2.21^{* * *} \\
(0.52)\end{array}$ & $1.91^{* * *}$ & $1.77 * * *$ & $2.09^{* * *}$ & $1.92^{* *}$ \\
& & & $(0.48)$ & $(0.38)$ & $(0.44)$ & $(0.81)$
\end{tabular}

Social Security Coverage

Financial Development

Shareholder Rights

Trust

Common Law

Observations

R-Squared
$0.29 * *$

$(0.14)$
0.006

$(0.047)$
$-0.045$

$(0.063)$

0.012

$(0.019)$

(0.010)

$0.33^{* * *}$

$(0.09)$

$0.29 * *$

$0.060^{*}$

0.063

(0.036) (0.067)

$\begin{array}{ccccccc}24 & 14 & 24 & 24 & 23 & 24 & 22 \\ 0.39 & 0.68 & 0.40 & 0.53 & 0.57 & 0.47 & 0.71\end{array}$

This table presents the estimates from the cross-country regression of stock market participation rates onto measures of insurance. The dependent variable, Stock Market Participation Rate, is constructed using countrylevel surveys conducted between 1997-2000 and reported in Giannetti and Koskinen (2007). Private Insurance is measured as the ratio of life and non-life insurance premiums to GDP as described in Beck, Demirguc-Kunt,and Levine (1999). Social Security Coverage is the average fraction of working age population covered by a social security program as reported by the World Bank (IEC) Database, 19871993. Other controls include Financial Development, Shareholder Rights, Trust, and Common Law. Financial Development is the ratio of total stock market capitalization to GDP in 1995. Shareholder Rights is measured using the anti-director rights index from La Porta, Lopez-de-Silanes, Shleifer, and Vishny (1998). Trust is the fraction of individuals in country that reply that 'most people can be trusted' as reported in the World Values Survey, 1995-1999. Common Law is an indicator equal to 1 if the legal origin of the country is English, as given by La Porta, Lopez-de-Silanes, Shleifer, and Vishny (1999). Bootstrapped standard errors are reported in parentheses. $* * *, * *$, and $*$ indicate statistical significance at the $1 \%, 5 \%$, and $10 \%$ level. 
Table 2

Saving Rates and Insurance

Dependent Variable = Private Saving Rate

\begin{tabular}{cccc}
\multicolumn{4}{c}{ All Countries } \\
\hline$(1)$ & $(2)$ & $(3)$ & $(4)$ \\
\hline \hline$-0.299 * * *$ & $-0.254 * * *$ & $-0.286^{* * *}$ \\
$(0.043)$ & $(0.049)$ & $(0.054)$
\end{tabular}

\begin{tabular}{cc} 
Low-Income & \multicolumn{1}{c}{ High-Income } \\
\hline \hline$(5)$ & $(6)$ \\
$-0.321 * * *$ & -0.128 \\
$(0.081)$ & $(0.491)$
\end{tabular}

Social Security Expenses

$-0.884 * * *$

(0.080)

$\log ($ GDP per capita)

$-0.037$

$-0.011$

0.037

0.026

$-0.029$

(0.032)

(0.026)

(0.027)

(0.051)

(0.029)

Financial Development

$\begin{array}{lc}-0.027 * * & 0.080 \\ (0.011) & (0.063)\end{array}$

0.041

$-0.025^{* *}$

$0.063)$

(0.049)

\begin{tabular}{lcccccc} 
Countries & 49 & 49 & 44 & 25 & 11 & 33 \\
Observations & 333 & 333 & 245 & 199 & 65 & 0.80 \\
R-Squared & 0.69 & 0.69 & 0.81 & 0.74 & 0.83 \\
\hline
\end{tabular}

This table presents the estimates from the country-level, fixed effects regression of private saving rates onto measures of insurance and year dummies. The dependent variable, Private Saving Rate, is constructed using the ratio of private saving to gross national disposable income reported by the World Savings Database, where private savings represents the difference between gross national savings and public sector savings. Private Insurance is the ratio of life and non-life insurance premiums to GDP as reported by the financial structure database produced by the World Bank. Social Security Expenses is the fraction of public expenditures spent on social security as reported by the World Bank (WEI) Database. Other controls include Log(GDP per capita) and Financial Development. GDP per capita is calculated using the IMF-IFS database, and Financial Development is the ratio of stock market capitalization to GDP reported in the financial structure database. In Column (5), the sample is restricted to countries classified as "Low Income" and "Lower Middle Income" by the financial structure database, and Column (6) restricts the sample to all other countries. Standard errors are clustered at the country level and reported in parentheses. $* * *, * *$, and $*$ indicate statistical significance at the $1 \%, 5 \%$, and $10 \%$ level. 


\section{Table 3}

\section{Stock Market Participation and Saving Rates}

Dependent Variable $=$ Stock Market Participation Rate

\begin{tabular}{lccc} 
& $(1)$ & $(2)$ & $(3)$ \\
\cline { 2 - 4 } Private Saving Rate & $-1.28^{* * *}$ & $-1.32^{* *}$ & $-1.61^{* * *}$ \\
& $(0.462)$ & $(0.642)$ & $(0.509)$ \\
Log(GDP per capita) & & 0.049 & 0.041 \\
& & $(0.039)$ & $(0.029)$ \\
Financial Development & & 0.115 \\
& & & $(0.098)$ \\
Observations & 19 & 18 & 17 \\
R-Squared & 0.26 & 0.48 & 0.62 \\
\hline
\end{tabular}

This table presents the estimates from the cross-country regression of stock market participation rates onto private saving rates. The dependent variable, Stock Market Participation Rate, is constructed using country-level surveys conducted between 1997-2000 and reported in Giannetti and Koskinen (2007). Private Saving Rate is constructed using the average ratio of private saving to gross national disposable income reported by the World Savings Database from 1990-1995, where private savings represents the difference between gross national savings and public sector savings. Other controls include Log(GDP per capita) and Financial Development. GDP per capita is calculated using the IMF-IFS database, and Financial Development is the ratio of stock market capitalization to GDP reported in the financial structure database.

Bootstrapped standard errors are reported in parentheses. ***, **, and * indicate statistical significance at the $1 \%, 5 \%$, and $10 \%$ level. 
Table 4

Stock Market Participation and Unemployment Insurance in the U.S.

\begin{tabular}{|c|c|c|c|c|}
\hline \multirow[t]{2}{*}{ Dependent Variable $=$} & \multirow{2}{*}{$\frac{\text { Stock Market Participation }}{(1)}$} & \multicolumn{3}{|c|}{ Abnormal Stock Market Participation } \\
\hline & & (2) & (3) & (4) \\
\hline UI Generosity & $\begin{array}{c}0.174 * * \\
(0.071)\end{array}$ & $\begin{array}{l}0.083^{*} \\
(0.046)\end{array}$ & $\begin{array}{r}0.096^{* *} \\
(0.049)\end{array}$ & $\begin{array}{l}0.094 * \\
(0.053)\end{array}$ \\
\hline$\%$ with College Education & & & $\begin{array}{l}-0.104 \\
(0.163)\end{array}$ & $\begin{array}{l}-0.101 \\
(0.180)\end{array}$ \\
\hline Log(Average Household Income) & & & & $\begin{array}{c}0.002 \\
(0.039)\end{array}$ \\
\hline Observations & 35 & 35 & 35 & 35 \\
\hline R-Squared & 0.16 & 0.12 & 0.13 & 0.13 \\
\hline
\end{tabular}

This table presents the estimates from a state-level regression of stock market participation rates onto unemployment insurance generosity. In column (1), the dependent variable, Stock Market Participation, is the fraction of households in a state that report owning stocks in the 1992 Health and Retirement Study. These rates were obtained directly from Hong, Kubik, and Stein (2004). In columns (2)-(4), the dependent variable, Abnormal Stock Market Participation, is the state-level residual from a household-level regression of a stock market participation indicator onto household characteristics such as age, income, wealth, race, etc. as reported in Hong, et al (2004). The right-hand side variable, UI Generosity, is the the logged value of average weekly unemployment benefits received in a state in 1992 as reported by the U.S. Department of Labor and calculated by Chetty (2007). Other state-level controls, obtained from the 1990 U.S. Census, include Log(Average Household Income) and percent of persons with some college education. Bootstrapped standard errors are reported in parentheses. ${ }^{* * *},{ }^{* *}$, and $*$ indicate statistical significance at the 1,5 , and $10 \%$ level. 


\section{Table 5}

\section{Participation, Unemployment Insurance, and Risk}

Dependent Variable = Abnormal Stock Market Participation

\begin{tabular}{lccc} 
& $(1)$ & $(2)$ & $(3)$ \\
\cline { 2 - 4 } UI Generosity & 0.011 & 0.013 & 0.007 \\
& $(0.072)$ & $(0.071)$ & $(0.080)$ \\
Risk Exposure & 0.012 & 0.003 & 0.001 \\
& $(0.013)$ & $(0.013)$ & $(0.014)$ \\
UI Generosity * Risk Exposure & $0.157^{*}$ & $0.186^{*}$ & $0.192^{* *}$ \\
& $(0.088)$ & $(0.098)$ & $(0.096)$ \\
\% with College Education & & & -0.218 \\
& & -0.207 & $(0.193)$ \\
Log(Average Household Income) & & $(0.202)$ & 0.003 \\
& & & $(0.052)$ \\
Observations & & & 35 \\
R-Squared & 35 & 35 & 0.26 \\
\hline
\end{tabular}

This table presents the estimates from a state-level regression of stock market participation rates onto unemployment insurance generosity and a measure of how many workers are employed in industries with negative job growth over the past five years. The dependent variable, Abnormal Stock Market Participation, is the state-level residual from a household-level regression of a stock market participation indicator onto household characteristics such as age, income, wealth, and race, as reported in Hong, Kubik, and Stein (2004). The right-hand side variable, UI Generosity, is the the demeaned logged value of average weekly unemployment benefits received in a state in 1992 as reported by the U.S. Department of Labor and calculated by Chetty (2007). Risk Exposure is an indicator equal to 1 for states with an above median fraction of workers in 1992 that are located in 2-digit industries that have seen drops in overall employees in the last five years as calculated using the 1987-1992 annual data reported by the U.S. Census Bureau in its County Business Patterns database. Other statelevel controls, obtained from the 1990 U.S. Census, include log(average household income) and the percent of persons with some college education. Bootstrapped standard errors are reported in parentheses. ${ }^{* * *}, * *$, and $*$ indicate significance at the 1,5 , and $10 \%$ level. 


\section{Table 6}

\section{Health, Life, and Long-Term Care Insurance}

Dependent Variable $=$ Stock Market Participation Indicator

\begin{tabular}{|c|c|c|c|c|}
\hline & $(1)$ & $(2)$ & (3) & (4) \\
\hline Employee Health Insurance & $\begin{array}{c}0.104 * * * \\
(0.012)\end{array}$ & & & $\begin{array}{c}0.102 * * * \\
(0.014)\end{array}$ \\
\hline Life Insurance & & $\begin{array}{c}0.130^{* * *} \\
(0.013)\end{array}$ & & $\begin{array}{c}0.105^{* * *} \\
(0.014)\end{array}$ \\
\hline Long-Term Care Insurance & & & $\begin{array}{c}0.127 * * * \\
(0.047)\end{array}$ & $\begin{array}{c}0.116^{* * *} \\
(0.048)\end{array}$ \\
\hline Age & $\begin{array}{c}0.001 \\
(0.001)\end{array}$ & $\begin{array}{c}0.001 \\
(0.001)\end{array}$ & $\begin{array}{c}0.001 \\
(0.001)\end{array}$ & $\begin{array}{c}0.002 \\
(0.001)\end{array}$ \\
\hline Education & $\begin{array}{c}0.031 * * * \\
(0.002)\end{array}$ & $\begin{array}{c}0.031 * * * \\
(0.002)\end{array}$ & $\begin{array}{c}0.031 * * * \\
(0.002)\end{array}$ & $\begin{array}{c}0.028^{* * *} \\
(0.002)\end{array}$ \\
\hline Race & $\begin{array}{c}-0.097 * * * \\
(0.013)\end{array}$ & $\begin{array}{c}-0.095^{* * *} \\
(0.013)\end{array}$ & $\begin{array}{c}-0.098^{* * *} \\
(0.013)\end{array}$ & $\begin{array}{c}-0.094 * * * \\
(0.013)\end{array}$ \\
\hline Marriage & $\begin{array}{l}-0.014 \\
(0.035)\end{array}$ & $\begin{array}{l}-0.042 \\
(0.036)\end{array}$ & $\begin{array}{l}-0.019 \\
(0.034)\end{array}$ & $\begin{array}{l}-0.044 \\
(0.037)\end{array}$ \\
\hline $\log ($ Wealth $)$ & $\begin{array}{c}0.137 * * * \\
(0.005)\end{array}$ & $\begin{array}{c}0.133^{* * *} \\
(0.005)\end{array}$ & $\begin{array}{c}0.135^{* * *} \\
(0.006)\end{array}$ & $\begin{array}{c}0.138^{* * *} \\
(0.006)\end{array}$ \\
\hline Log(Income) & $\begin{array}{c}0.033^{* * *} \\
(0.009)\end{array}$ & $\begin{array}{c}0.041^{* * *} \\
(0.009)\end{array}$ & $\begin{array}{c}0.051^{* * *} \\
(0.009)\end{array}$ & $\begin{array}{c}0.030^{* * *} \\
(0.009)\end{array}$ \\
\hline Observations & 9484 & 9427 & 8930 & 8816 \\
\hline R-Squared & 0.20 & 0.20 & 0.20 & 0.21 \\
\hline
\end{tabular}

This table presents the marginal effect estimates from a U.S. household-level Probit regression of stock market participation rates onto measures of insurance coverage. The dependent variable, Stock Market Participation, is an indicator that equals one if the household reports owning stocks in the 1992 Health and Retirement Study. Employee Health Insurance, Life Insurance, and Long-Term Care Insurance are indicators equal to one if the household reports having a such an insurance policy. Age is the age of the oldest member in the household. Education is the largest number of years of education obtained by a household member. Race is an indicator equal to one if any household member is non-white. Marriage is an indicator equal to one if the respondent for the household reports being married. Wealth is the household's total reported wealth including property. Income is the total household income reported. Robust standard errors are reported in parentheses. ${ }^{* * *},{ }^{* *}$, and ${ }^{*}$ indicate statistical significance at the $1 \%, 5 \%$, and $10 \%$ level. 